\title{
Exhaust Ventilation through a Solar Chimney: A Response to High Hermeticity in Welfare Housing
}

\author{
Marcos Eduardo Gonzalez-Trevizo ${ }^{1}$, Adolfo Gomez-Amador ${ }^{2}$, Anibal Luna-Leon ${ }^{3}$, Carlos Escobar-Del Pozo ${ }^{4}$ and \\ Carlos Javier Esparza Lopez ${ }^{2}$ \\ 1. Facultad de Arquitectura (Faculty of Architecture), Universidad Michoacana de San Nicolás de Hidalgo (Michoacan University \\ of Saint Nicholas of Hidalgo), Morelia MN 58030, Mexico \\ 2. Facultad de Arquitectura y Diseño (Faculty of Architecture and Design), Universidad de Colima (University of Colima), Colima \\ CL 28400, Mexico
}

3. Facultad de Arquitectura y Diseño (Faculty of Architecture and Design), Universidad Autónoma de Baja California (Baja California Autonomous University), Mexicali BC 21280, Mexico

4. Facultad de Ingenieria Mecánica y Eléctrica (Faculty of Mechanical and Electrical Engineering), Universidad de Colima, Colima CL 28400, Mexico

\begin{abstract}
This research reports on potentiality in the solar chimney as an exhaust ventilation device through a hypothetical statement that convenient weather conditions exist on sub-humid warm climate to enhance the performance of a SC (solar chimney), in order to increase ventilation to dissipate metabolic heat from inhabitants of airtight buildings. The methodology used in this research integrates the use of simplified mathematical models that predict in a semi-empirical way a potential volume flow through estimation of kinetic power generation, by natural circulation and stack effect in a typical covered-plate air solar collector. The study was carried out during the warm month of April, an important warm season for Colima, where the prevailing wind is about $6.8 \mathrm{~m} / \mathrm{s}$, the average temperature of maximums and minimums oscillates between $15.4{ }^{\circ} \mathrm{C}$ and $34.4{ }^{\circ} \mathrm{C}$ with average relative humidity of $65 \%$ according to national weather service. A scale model of the SC was installed on environmental chambers. The results showed that this device is capable of generating ventilation conditions around light breeze parameters near between $0.6 \mathrm{~m} / \mathrm{s}$ and $1.5 \mathrm{~m} / \mathrm{s}$ width, a better performance at day in $45 \%$ approximately than the night values, making ventilation rates up $0.24 \mathrm{ACH}$ (air changes per hour) as average air change rate.
\end{abstract}

Key words: Exhaust ventilation, solar chimney, air solar collector, welfare housing.

\section{Introduction}

With an estimated population of over 112 million, Mexico has $76 \%$ of its people concentrated in urban areas, whose housing demand will be reached through construction schemes at low cost, guided both on economic criteria and structural safety that reduce habitability parameters, such as natural ventilation.

In compliance with Köppen-García's climatic classification system, Mexico has nearly 60 different types of climates, divided into four climatic groups

Corresponding author: Marcos Eduardo Gonzalez-Trevizo, M.Sc., research fields: architecture and environment. E-mail: gonzalez_marcos@ucol.mx. based on average temperature and rainfall [1].

To illustrate this, annual rainfall conditions exist from $183 \mathrm{~mm}$ in Baja California up to 2,010 $\mathrm{mm}$ in Villahermosa according to Mexico National Weather Service [2].

It is important to note that almost $40 \%$ of urban population in Mexico live in two metropolitan areas: the valley of Mexico and Guadalajara, where prevailing climates are semi-warm with annual rainfall between $827 \mathrm{~mm}$ and $947 \mathrm{~mm}$, average temperatures from $18.1{ }^{\circ} \mathrm{C}$ to $19.7^{\circ} \mathrm{C}$ and, at the same time, the $98 \%$ of remarkable seismic activities are present in national urban areas [3]. While structural 
safety regulations in the rest of Mexico commonly derived from these metropolitan areas, thermal behavior in buildings is a factor poorly studied, generating a problematic contradiction.

As an example, safety conditions dictate one unbalanced relationship between openings and walls (ratio $1-1 / 20$ as minimum in Mexico City), but weather conditions suggest very different solutions. Such is the case of the criteria for the use of natural ventilation and thermal mass.

Although Mexico has a potential use of solar energy, as the daily average solar radiation is $4.8 \mathrm{kWh} / \mathrm{m}^{2}$ to $5.6 \mathrm{kWh} / \mathrm{m}^{2}$ in the horizontal surface and urban ventilation is close to $8.0 \mathrm{~m} / \mathrm{s}$, little advantage of these conditions is taken. Building code guidelines to achieve direct minimum health conditions, but are still very far from seeking hygrothermal comfort of the inhabitants.

Yet, withal, many recent studies have shown the possibility of using the aforementioned weather conditions to favor improving habitability through passive ventilation. Examples of this are SC (solar chimneys) that were commonly used only as power plants.

Both in solar chimneys and flat plate collector designs, the solar radiation on exposed surfaces as the main heat input is proportional to the irradiance collected. The most important objective is to maximize the absorption coefficient and the thermal storage capacity from the available surface mass.

Recently, mathematical models, such as those developed for predicting the velocity of airflow in a solar chimney through the prediction of temperature, air flow channel and the glass cover have shown interesting facts in India.

To produce such models, a solar chimney with less than $1 \mathrm{~m}$ high absorber and three different opening combinations of air gap and size of the air inlet opening were used. With this, speeds up to $0.24 \mathrm{~m} / \mathrm{s}$ were observed in the experiment: a compelling approximation of the mathematical model prediction
[4].

Studies in Asia also documented the thermal performance of a solar chimney with glass walls in a small $2.8 \mathrm{~m}^{3}$ module.

With dimensions as follows: $0.74 \mathrm{~m}$ high, $0.50 \mathrm{~m}$ wide and $0.10 \mathrm{~m}$ deep and air opening, the size of the openings was $0.50 \mathrm{~m} \times 0.50 \mathrm{~m}$. With two clear glasses $0.006 \mathrm{~m}$ thick, the velocity ranges indicated that measures of induced air flow rates were among $0.13 \mathrm{~m}^{3} \sim 0.28 \mathrm{~m}^{3}$.

The difference between indoor and ambient temperature was less than when a single layer of clear glass was used, indicating the effect on the further use of crystals with respect to the opaque faces of the absorber [5].

The research institute of India indicated in their research that scale solar chimneys, when increasing the ratio between the height and the hole between the glass and the collector, increased ventilation which was also caused by the device. This conclusion was compared with modeled results for the analysis of the system.

Subsequently, Jyotirmay et al. [6] studied the effect of the inclination of the collector in the airflow in a ventilation system naturally induced. Using an RSC (roof solar chimney) concept during summer due to the solar height, a collector plate with a small inclination captures more sunlight, but decreases its effectiveness by the reduction of the height of the stack. Thus, the results showed that maximum ventilation was found between $40^{\circ}$ and $60^{\circ}$ inclinations, depending on the latitude of the site. Previous research showed that 1:12 scale models had values close to those offered by theoretical models. Numerical calculations showed that a solar collector of $2.25 \mathrm{~m}^{2}$ with $30^{\circ}$ inclination was able to induce $140 \mathrm{~m}^{3} / \mathrm{h}$ and $330 \mathrm{~m}^{3} / \mathrm{h}$ with a radiation of $200 \mathrm{~W} / \mathrm{m}^{2}$ and $1,000 \mathrm{~W} / \mathrm{m}^{2}$, respectively.

Recent literature shows the relationship between the speed reached into the chimneys and the temperatures recorded may be estimated. 
Mathematical models may yield prediction for the improvement of such devices through the modification of any of its elements. The purpose of this study is to determine experimentally that a solar chimney with a flat plate collector has the potential to be used in a warm sub-humid climate, where thermal oscillation range is less significant than in arid climates.

\section{Method}

\subsection{Placement}

The experiment was developed by using experimental test chambers located in Coquimatlan, Colima, inside the University of Colima, a suburban area together with Colima City: $103^{\circ} 48^{\prime} \mathrm{W}, 19^{\circ} 12^{\prime} \mathrm{N}$ and $365 \mathrm{~m}$ above sea level (Fig. 1).

The weather conditions in the region are described as warm sub-humid according to Köppen-García's climatic classification system. In this climate, where the relative humidity reaches percentages above $50 \%$, non-ventilated living spaces significantly degrade the living conditions at critical seasonal periods of the year, i.e., when the air temperature is close to the average skin temperature $\left(38^{\circ} \mathrm{C}\right)$. In order to delimit the most critical season, it is possible to correlate variables, such as DBT (dry-bulb temperature) and relative humidity.

For the area of Colima, the situation described above is particularly true during the spring season, in other words, from March to May. According to a TMY (typical meteorological year) simulated through spatial interpolation methods in Meteonorm ${ }^{\circledR}$ software, the mean temperatures oscillate from $23.8{ }^{\circ} \mathrm{C}$ in March through $26.3{ }^{\circ} \mathrm{C}$ in May, while mean $R H$ (relative humidity) values oscillate from $67.9 \%$ in March through 69.7\% in May.

Fig. 2 also shows global horizontal radiation values, where April is appreciated as the month with the highest value: $267.84 \mathrm{Wh} / \mathrm{m}^{2}$ during spring and the whole year as well.

Under this weather condition, it was possible to identify that the month of April provides the maximum total solar radiation, useful to generate exhaust ventilation through natural convection processes, as those used in solar plants focused on energy production.

However, it is of fundamental interest to know the total radiation, not only in the horizontal surface, conventionally produced by weather stations.

For this, it is necessary to study different numerical models which use the same techniques for projecting the beam and ground reflected radiation onto a tilted surface. They differ only in the calculation of diffuse radiation.

Thus, the total radiation incident on a tilted flat surface is composed as Eq. (1) below:

$$
I_{T}=I_{b T}+I_{d T}+I_{g T}
$$

where, $I_{T}$ is the total radiation on a tilted surface, while $I_{b T}$ is the beam radiation, $I_{d T}$ is the diffuse radiation and $I_{g T}$ is the ground reflected radiation.

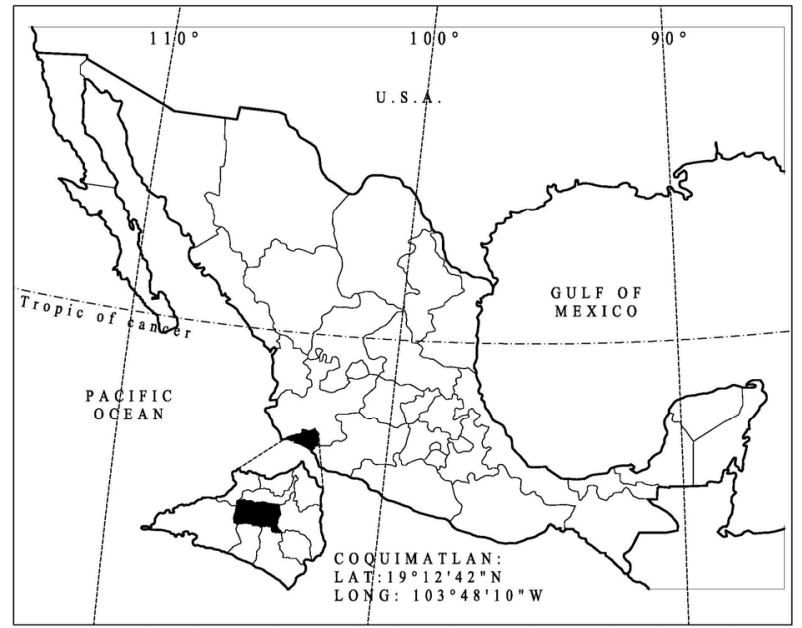

Fig. 1 Geographic location of Coquimatlan, Colima.

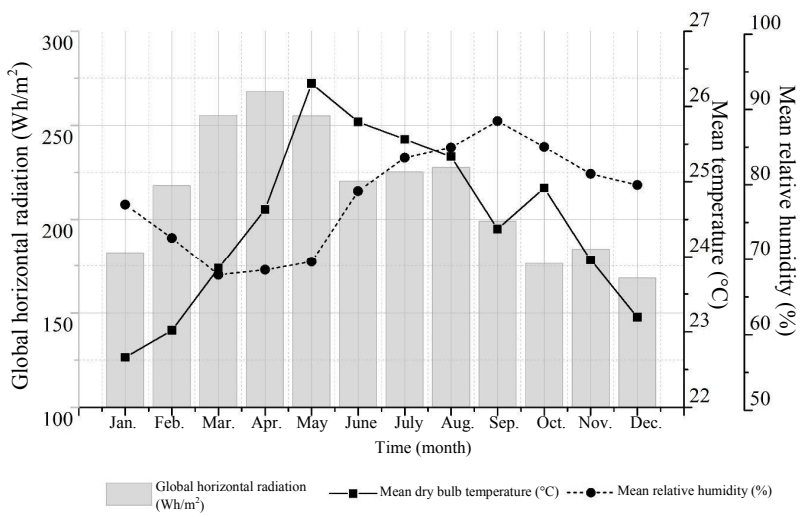

Fig. 2 Climate conditions of Coquimatlan, Colima. 
Given that, for the purposes of this research, the radiation model developed by Perez et al. [7] to calculate total incidence on tilted surfaces was used through the radiation processors type included in TRNSYS $^{\circledR}$ software. This anisotropic sky model accounts for circumsolar, horizon brightening and isotropic diffuse radiation providing accurate predictions $[8,9]$.

Eq. (2) shows the estimation of diffuse radiation on tilted surface cited above, including aspects such as the reduced brightness sky coefficients and other parameters as follows:

$$
I_{d T}=I_{d}\left[0.5\left(1-F_{1}^{\prime}\right)(1+\cos \beta)+F_{1}^{\prime}\left(\frac{a}{c}\right)+F_{2}^{\prime} \sin \beta\right]
$$

where, $I_{d}$ is the diffuse radiation on horizontal surface, $F_{1}{ }^{\prime}$ is the reduced brightness coefficient (circumsolar), $F_{2}{ }^{\prime}$ is the reduced brightness coefficient (horizon brightening), $a / c$ is the weighted circumsolar solid angle and $\beta$ is the slope of the surface.

By using this mathematical model, this research calculates the annual total radiation on different tilted surfaces, with 19 different tilt angles: from $0^{\circ}$ to $90^{\circ}$ with $5^{\circ}$ increments, and 40 different azimuths, from $0^{\circ}$ to $360^{\circ}$ with $10^{\circ}$ increments, but including middle orientations northeast, southeast, southwest and northwest to conform a total of 760 cases, with values interpolated in Fig. 3.

This polar chart provides values from 521 to 1,954 $\mathrm{kWh} / \mathrm{m}^{2} /$ year, which allows to find the optimum tilt angle and azimuth, in order to take advantage of total radiation on a tilted surface. For the area of Colima, this configuration was found at $0^{\circ}$ azimuth (south) with a $20^{\circ}$ tilt angle.

It is important to observe the prevailing winds, because of its convective effects. As seen in Fig. 4, the dominant winds come from $70^{\circ}$ azimuth with a mean speed value of $1.9 \mathrm{~m} / \mathrm{s}$ and $7.4 \%$ as the speed weighted percentage.

\subsection{Test Modules}

In order to test the potential of a device which takes advantage of the prior conditions, an experimental scenario was arranged using two test chambers. The specific design features of both of them obey the 1:2 scale representation of a room with the minimum acceptable dimensions of habitability requirements of Colima's building code. Test chambers have $2.46 \mathrm{~m}^{3}$ volume: $1.35 \mathrm{~m}, 1.35 \mathrm{~m}$ and $1.35 \mathrm{~m}$ (length $\times$ depth $\times$ height). They have a front opening, it is $0.50 \mathrm{~m}$ by $1.05 \mathrm{~m}$ to provide the necessary air inlet to enable an inhibited cross-ventilation state (Fig. 5).

The materials employed are traditionally used in Colima, clay brick walls and concrete slab on the roof, with parapets whose height is $0.10 \mathrm{~m}$, walls painted in white color. Each of the chambers is individually

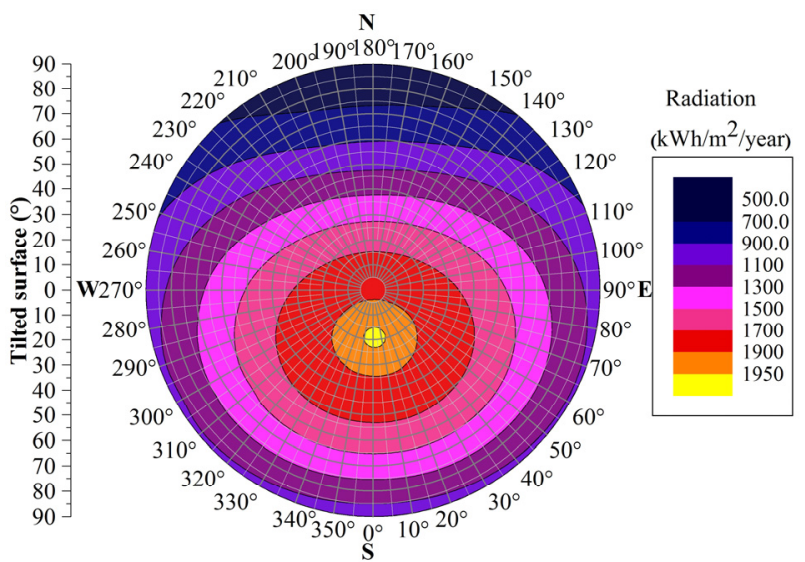

Fig. 3 Annual total solar radiation on different tilted surfaces in Coquimatlan, Colima (Perez radiation model).

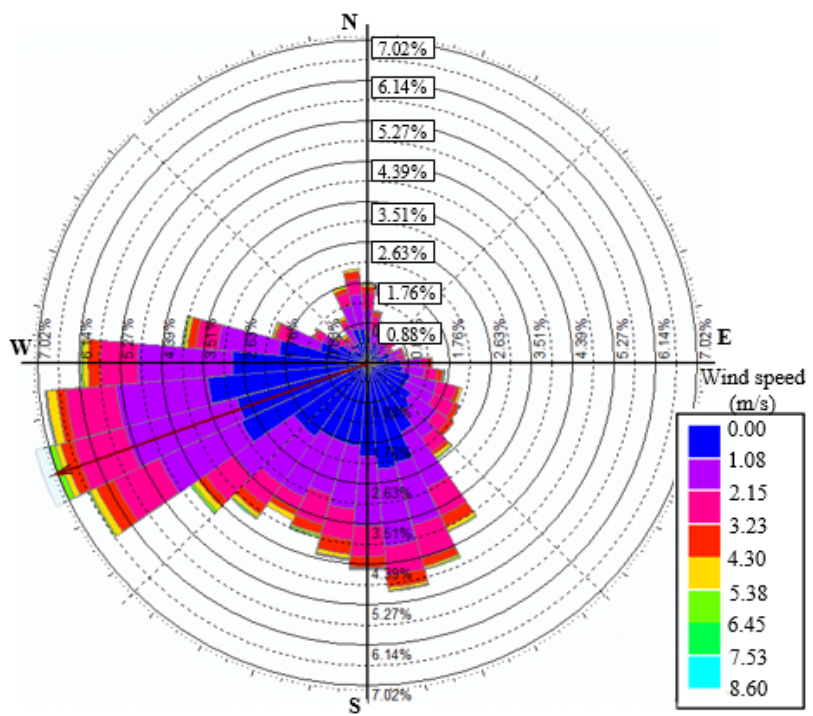

Fig. 4 Prevailing winds in Coquimatlan, Colima. 


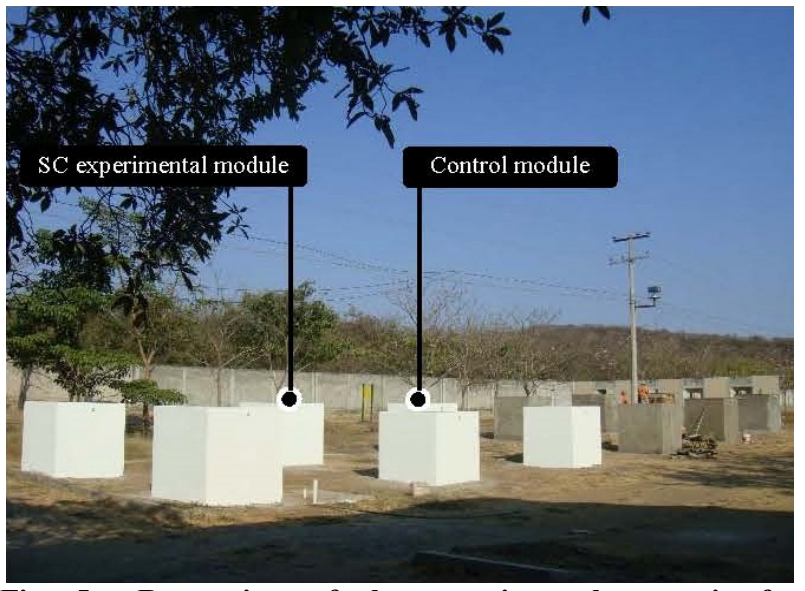

Fig. 5 Rear view of the experimental scenario for field-testing, location: University of Colima.

capable of offering almost identical weather conditions. To achieve that, a solar geometry evaluation was developed before their construction.

\subsection{Data Logging Equipment}

The instruments used to capture and record weather information detect wind and temperature variations with a high degree of sensitivity. These were located inside the test and experimental chamber respectively to see the ventilation changes generated by the subsequently proposed device.

An HD2103.2 Delta Ohm ${ }^{\circledR}$ unidirectional hot-wire anemometer-thermometer with a flexible telescopic probe and DBT sensor range from $-30{ }^{\circ} \mathrm{C}$ to $110{ }^{\circ} \mathrm{C}$, speed wind of $0.0 \sim 40.0 \mathrm{~m} / \mathrm{s}, \pm 0.2 \%$ accuracy, was used. Additionally, a U12-012 ONSET HOBO ${ }^{\circledR}$ data logger with temperature sensor range from $-20{ }^{\circ} \mathrm{C}$ to $70{ }^{\circ} \mathrm{C}, \pm 0.35{ }^{\circ} \mathrm{C}$ accuracy, $\mathrm{RH}$ range from $5 \%$ to $95 \%$, $\pm 2.5 \%$ accuracy dry-bulb temperature due to passive ventilation, was used (Fig. 6).

To ensure the validity of the experiment, wind conditions of the control and experimental modules were compared, they showed an acceptable similarity: sample size of $N=2,880$, sample mean value of $\bar{x}=$ 0.05 and a standard deviation of $\sigma=0.086$ (Fig. 7).

\section{Experiment}

Once the experimental set up to investigate was built, the scale and design of the solar chimney was arranged considering the aspects of proportion (Fig. 8). The theoretical basis of this prototype was given by the thermo-siphon principle and simplified by the equation below:

$$
Q=\rho \mathrm{g} \Delta T
$$

where, $Q$ is the volume flow rate, $\rho$ is the air density, $\mathrm{g}$ is gravitation constant and $\Delta T$ is the dry-bulb temperature gradient.

Thus, the design of the air collector was based on the observation of the flat solar collector typical design, used to produce electrical or thermal energy, where: (a) screen made of $0.30 \mathrm{~m} \times 0.31 \mathrm{~m}$ clear glass, $0.003 \mathrm{~m}$ thick, as convective cooling protector for the air collector; (b) metallic flat plate collector (absorber)

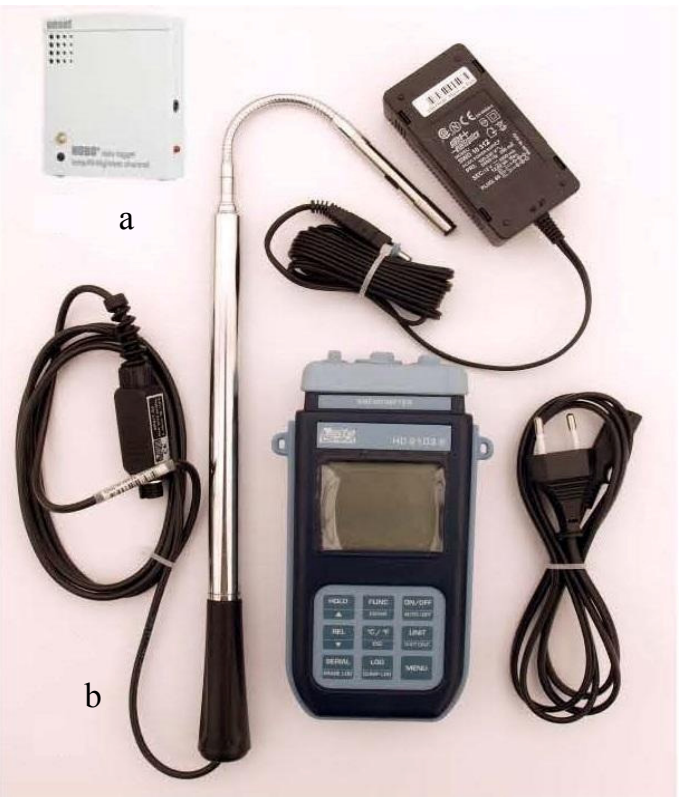

Fig. 6 Data logging equipment (a: data logger; b unidirectional hot-wire anemometer-thermometer).

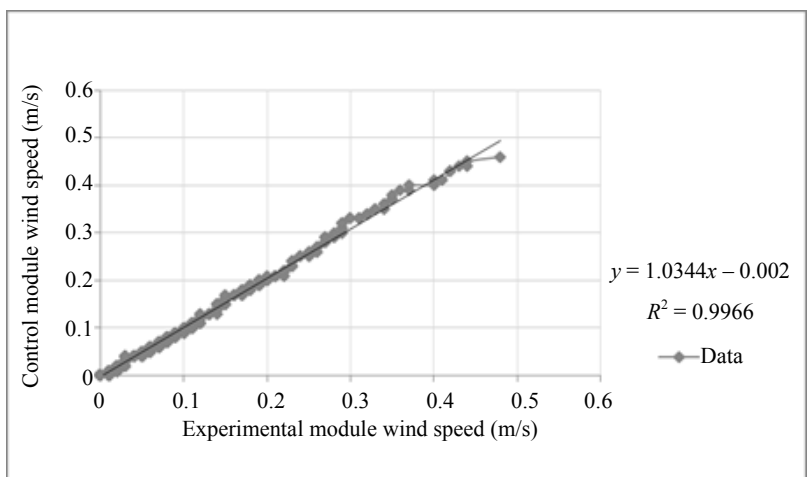

Fig. 7 Wind conditions between experimental and control module with a linear trend line indicating the correlation. 


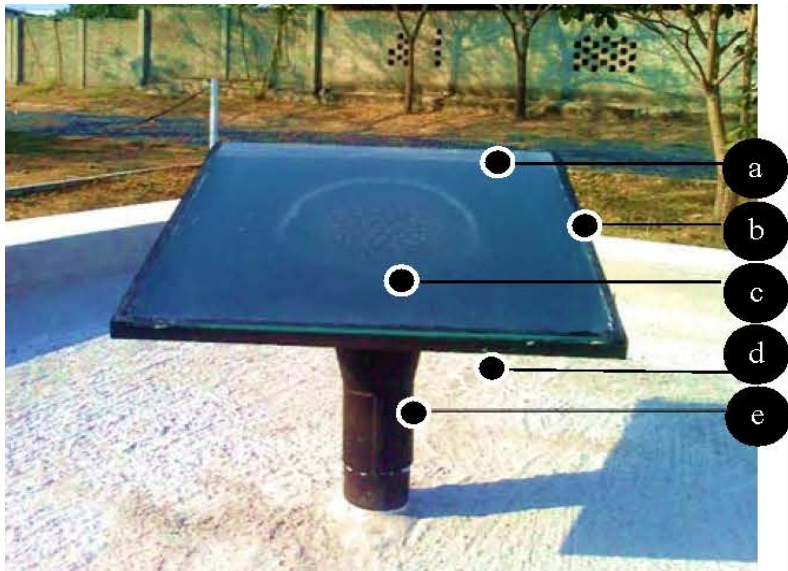

Fig. 8 SC design based on the covered-plate type solar collector.

of $0.30 \mathrm{~m} \times 0.31 \mathrm{~m}$ made of stainless steel (gauge 26) with enamel paint on matte black color and $20^{\circ}$ plate's slope; (c) wind output channel, based on 56 perforations, with a diameter of $3 / 16 " \varnothing$ distributed concentrically in a $3 "$ diameter circle on the flat plate collector; (d) environmental testing chamber roof; (e) extraction channel (2"Ø) manufactured from stainless steel (gauge 26) with enamel paint on matte black color and $0.165 \mathrm{~m}$ height.

Even when steel is not the most conductive material used to build collector's plate, it implies a radiant energy absorption around $0.40 \sim 0.65$ and an infrared emittance $0.20 \sim 0.30$ is the least expensive compared to copper and aluminum, a remarkable factor for the low-income housing policies. To complete the setup, the equipment was located in Fig. 9, where, $x$ is the ventilation device, $y$ is the probe of the unidirectional hot wire anemometer-thermometer, and $z$ is the data logger.

After this, the relevant monitoring period was also determined to conduct performance of the ventilation device. The month of April when sun provides 194.16 $\mathrm{kWh} / \mathrm{m}^{2} /$ month as a maximum total radiation value is able to supply $189.69 \mathrm{kWh} / \mathrm{m}^{2} /$ month for a collector plate with an angle of inclination of $20^{\circ}$ oriented due south.

The frequency of wind and temperature capture was fixed for each minute of the day to form a daily profile based on 1,440 records of each day of April in the spring of 2011.

With the information obtained, April 5th was selected as a representative day within the same sample that met the approximate mean temperatures reflected by the weather data for this month, taking into account the mean maximum and minimum temperatures and typical day limits sought within records in question.

\section{Results}

The results showed an expected natural behavior, the more solar radiation increases, the more solar chimney increases its performance, with presence of wind gusts within the 7-9 $\mathrm{h}$ and 12-19 $\mathrm{h}$.

Fig. 10 shows records obtained in the experimental chamber, from a sample of $N=1,440, x_{1}=0.13 \mathrm{~m} / \mathrm{s}$, $x_{1,440}=0.07 \mathrm{~m} / \mathrm{s}$ and $\bar{x}=0.08 \mathrm{~m} / \mathrm{s}$ show a trend line with a constant minimal increasing behavior.

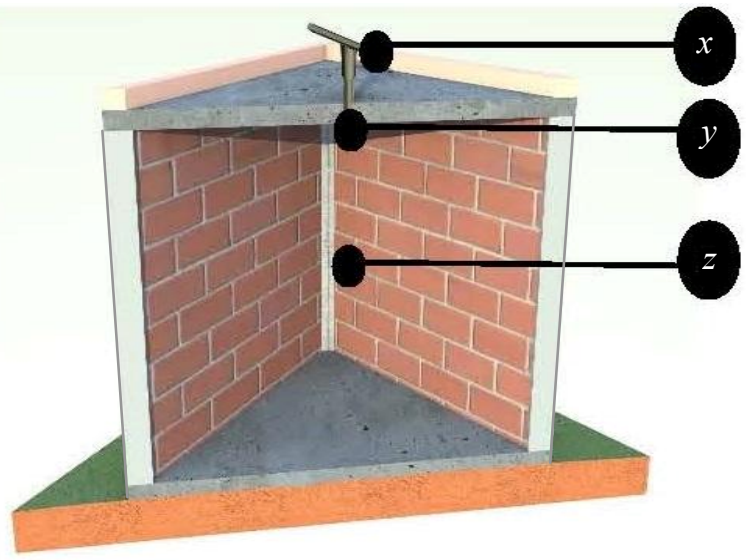

Fig. 9 Data logging equipment installation.

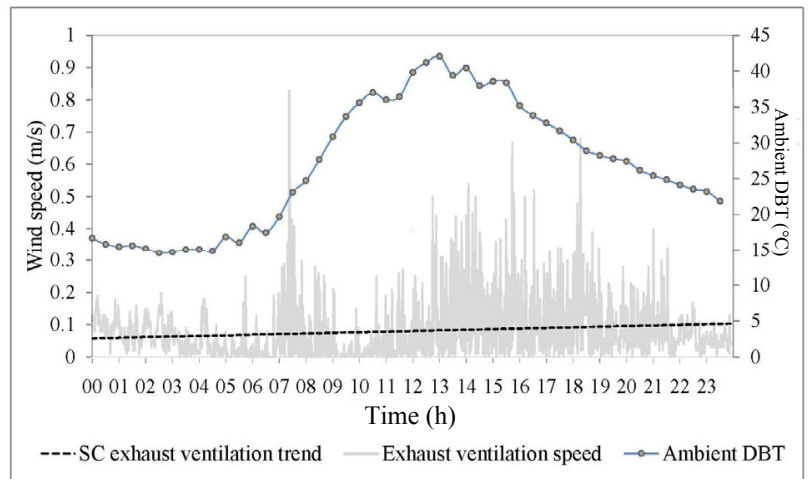

Fig. 10 Solar chimney ventilation on experimental module in a typical day conditions. 
Table 1 Daily performance of the solar chimney based on results.

\begin{tabular}{lr}
\hline Concept & Value \\
\hline Total air volume extracted $\left(\mathrm{m}^{3}\right)$ & 14.07 \\
Air volume extracted at day $\left(\mathrm{m}^{3}\right)$ & 8.32 \\
Air volume extracted at night $\left(\mathrm{m}^{3}\right)$ & 5.75 \\
Total air changes & 5.72 \\
Air changes at day & 3.38 \\
Air changes at night & 2.34 \\
Average air change rate $($ a.c. $/ \mathrm{h})$ & 0.24 \\
Average air change rate at day (a.c./h) & 0.27 \\
Average air change rate at night (a.c. $/ \mathrm{h})$ & 0.20 \\
\hline
\end{tabular}

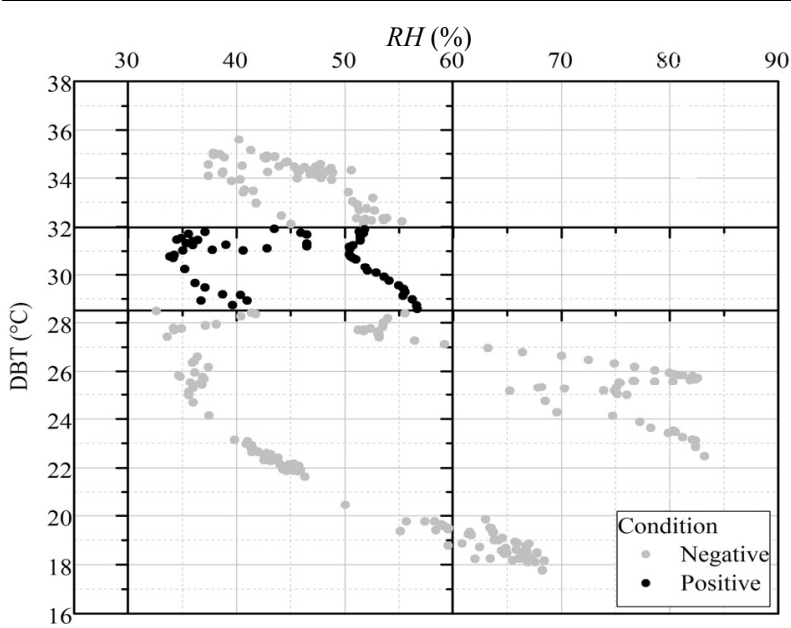

Fig. 11 Air hygrothermal potential in the outside ambient during the experimentation.

Records obtained, excluding calm conditions, show magnitudes near $0.83 \mathrm{~m} / \mathrm{s}$ as maximum values during day time, while $0.3 \mathrm{~m} / \mathrm{s}$ and similar values were recorded at night. It is important to identify this, because the thermal mass effects of the flat plate collector and the flow channel were disregarded in designing.

The average wind speed recorded was near $0.1 \mathrm{~m} / \mathrm{s}$ due to the calm periods. A slight difference in the thermal behavior of the modules $\left(1{ }^{\circ} \mathrm{C}\right)$ was also observed. However, the trend of thermal behavior in both modules was practically identical.

The interpretation of the results leads to the performance calculation, which shows the potential of this device in Table 1. The estimation was obtained using Eq. (4) defined by ANSI/ASHRAE (the American National Standards Institute and the American Society of Heating, Refrigerating, and
Air-Conditioning Engineers) Standard 62.2-2013 for low-rise residential buildings in SI (system international) units:

$$
N=3,600 q / V
$$

where, $N$ is the number of air changes per hour, $q$ is the volumetric flow rate of air in cubic meters per minute and $V$ is the space volume in cubic meters.

\section{Discussions}

The results showed a consistent trend in the passive ventilation provided by the $\mathrm{SC}$, although the values were low. Nocturnal behavior of the device was more flattering than it could have been estimated, considering the absence of solar radiation (45\% less than shown at day) and the low thermal mass involved.

Because of this, the clear definition of natural ventilation as selective strategy is worthy, due to its direct relation with the compatibility between outside conditions and any passive ventilation device (Fig. 11).

To emphasize it, the daily data can be grouped in compliance with two simple conditions, just to illustrate the need of a method to decide if the air introduced into the building should be treated or not. The first is based on epidemiological, clinical and climate studies that indicate $R H$ between $30 \% \sim 60 \%$ is the appropriate range to maintain an acceptable indoor air quality [9].

The second condition is based on the thermoneutral zone definition, the range of ambient temperature at which human thermoregulation is achieved only by control of sensible heat loss, i.e., between $28.5 \sim 32{ }^{\circ} \mathrm{C}$ DBT [10].

When these conditions were overlapping, the outside air temperature was considered positive and ready to be used and if not, it was considered negative. At the day of the experiment, RH and DBT values per minute were recorded. The positive values took place from 09:25 $\mathrm{h}$ through 11:40 $\mathrm{h}$ and finally from $17: 10 \mathrm{~h}$ through 19:10 $\mathrm{h}$ when wind speed reaches its high magnitude.

It is important to note that additional strategies can 
be taken to improve the hygrothermal conditions of the outside ambient to increase the positive values before the air is taken, such as green walls or solar protections.

\section{Conclusions}

The described information above allows appropriate adjustments to the SC design, through the extension of the flat plate collector, the flow channel and constructive aspects, such as thermal mass or even in the number of ventilation devices per room.

Thus, the operation of a solar chimney or air collector depends not only on solar radiation, but also on a convenient regimen of selective use in the months and relevant hours for this type of devices. Therefore, strategies can be assumed to cool, heat, humidify or dehumidify the air before its injection in habitable areas.

While thermosyphon effect is exploited to facilitate exhaust ventilation only, the literature reviewed shows signs that lead to research that solar chimneys are devices that are part of more complex composite systems which can change not only the inner air change rate through exhaust ventilation, but also the relative humidity and dry bulb temperature.

Because of that, it is highly advisable for future applications to study SC within composite systems and its interaction not only on single rooms, but in complete habitable areas to identify the effects on complex indoor environments.

\section{Acknowledgments}

The authors would like to express their thanks to Ph.D. Ignacio Guillermo Galindo Estrada for his support in the Colima University Centre for Environmental Science Research (CUICA for its acronym in Spanish).

\section{References}

[1] Enriqueta, G. 2013. "Comisión Nacional Para el
Conocimiento y Uso de la Biodiversidad (CONABIO) (The National Commission for Knowledge and Use of Biodiversity: Catalogue of Geographic Metadata)." The National Commission for Knowledge and Use of Biodiversity. Accessed August 9, 2013. http://www.conabio.gob.mx/informacion/metadata/gis/cli malmgw.xml?_xsl=/db/metadata/xsl/fgdc_html.xsl\&_ind ent $=$ no. (in Spanish)

[2] Servicio Meteorológico Nacional (National Weather Service). 2013. "Weather Station Standardized Data." Servicio Meteorológico Nacional. Accessed August 9, 2013.

http://smn.cna.gob.mx/index.php?option=com_content\&v iew $=$ article $\&$ id $=42 \&$ Itemid $=75$.

[3] Servicio Sismológico Nacional. 2013. "Catalogue." Servicio Meteorológico Nacional. Accessed August 12, 2013. http://www2.ssn.unam.mx:8080/website/jsp/ catalogo1.jsp.

[4] Bansal, N. K., Mathur, J., Mathur, S., and Jain, M. 2005. "Modeling of Window-Sized Solar Chimneys for Ventilation." Building and Environment 40: 1302-8.

[5] Chantawong, P., Hirunlabh, J., Zeghmati, B., Khedari, J., Teekasap, S., and Win, M. 2006. "Investigation on Thermal Performance of Glazed Solar Chimney Walls." Solar Energy 80: 288-97.

[6] Mathur, J., Mathur, S., and Anupma. 2006. "Summer-Performance of Inclined Roof Solar Chimney for Natural Ventilation." Energy and Buildings 38: 1156-63.

[7] Klein, S. A., Beckman, W. A., Mitchell, J. W., Duffie, J. A., Duffie, N. A., Freeman, T. L., et al. 2007. TRNSYS 16: A Transient System Simulation Program. USA: University of Wisconsin-Madison: 280-281.

[8] Loutzenhiser, P. G., Manz, H., Felsmann, C., Strachan, P. A., Frank, T., and Maxwell, G. M. 2007. "An Empirical Validation of Models to Compute Solar Irradiance on Inclined Surfaces for Building Energy Simulation.” Solar Energy 81: 254-67.

[9] Khalil, S., and Shaffie, A. M. 2013. "A Comparative Study of Total, Direct and Diffuse Solar Irradiance by Using Different Models on Horizontal and Inclined Surfaces for Cairo, Egypt." Renewable and Sustainable Energy Reviews 27: 853-63.

[10] Wolkoff, P., and Kjærgaard, S. 2007. "The Dichotomy of Relative Humidity on Indoor Air Quality.” Environment International 33: 850-7.

[11] Boris, K. 2012. Human Thermoregulation: A Synergy between Physiology and Mathematical Modelling. Maastricht: Maastricht University Press. 